Artigo Original

Original Article

\title{
Esporte universitário: percepção de atletas sobre os modelos brasileiro e canadense
}

\section{University Sports: Brazilian and Canadian Models under Athletes' Perception}

Maria Juliana de Almeida Robalinho ${ }^{1,2,3}$; Leandro de Lima e Silva ${ }^{\$ 1,2,3}$; Eduardo Borba Neves ${ }^{2,4} \mathrm{PhD}$; Rodrigo G. S. Vale ${ }^{1,2,3} \mathrm{PhD}$; Rodolfo de Alkmim Moreira Nunes ${ }^{1,2,3} \mathrm{PhD}$

Recebido em: 09 de abril de 2018. Aceito em: 17 de maio de 2018.

Publicado online em: 05 de julho de 2018.

\section{Resumo}

Introdução: 0 esporte universitário tem um papel muito importante no cenário esportivo mundial. No Canadá, o esporte universitário teve início há poucos anos e já vem colhendo frutos no esporte profissional. Embora, no Brasil, o modelo de esporte universitário apresente semelhanças, porém não tem exibido sucesso.

Objetivo: Comparar a situação atual do esporte universitário no Brasil e no Canadá, por meio da percepção de jovens que tiveram a experiência de participar do esporte universitário em ambos os países.

Métodos: Quatorze alunos que tiveram a oportunidade de vivenciar o esporte universitário em ambos os países (Brasil e Canadá). Foi elaborado um questionário estruturado, este aplicado duas vezes, sendo uma para cada país. As perguntas foram segmentadas nas dimensões: logística de treinamento, dimensões estruturais, dimensões de jogo, dimensões organizacionais e dimensões gerais. 0 índice de confiabilidade do instrumento foi verificado através do coeficiente alfa de Cronbach. Foi utilizado o teste de Wilcoxon para verificar diferença estatística significativa entre os questionários.

Resultados: As respostas dos alunos às assertivas que compuseram o questionário sobre o esporte universitário

\section{Pontos-Chave Destaque}

- Foi desenvolvido um questionário para avaliar o modelo de esporte universitário abrangendo cinco dimensões estruturais.

- Os escores alcançados exibiram a diferença na estrutura oferecida em ambos os países. Brasil: 30,93 e Canadá: 76,94. - As diferenças estatisticamente significativas encontradas indicaram os pontos deficientes no modelo brasileiro. apresentam caráter mais negativo para o Brasil alcançando um total de escore de 30,93 contra 76,64 do Canadá. Neste último país, em todas as dimensões os escores exibidos foram superiores aos reportados pelos atletas em relação ao Brasil. A diferença em relação ao esporte universitário dos países foi estatisticamente significativa $(\mathrm{p}<0,05)$.

Conclusão: Concluiu-se que as faculdades no Canadá apresentam um modelo de estrutura de esporte universitário mais favorável ao desenvolvimento do esporte de alto rendimento no país, possuindo departamento esportivo, voltado diretamente para os times universitários, área acadêmica e área esportiva trabalhando em conjunto. Tal estrutura falta no modelo brasileiro de esporte universitário representando obstáculo para o sucesso do esporte nacional.

Palavras-chave: esporte, universidade, atletas.

\footnotetext{
$\S$ Autor correspondente: Leandro de Lima e Silva - e-mail: I.limaesilva@gmail.com Afiliações: ${ }^{1}$ Universidade do Estado do Rio de Janeiro (PPGCEE/UERJ); ${ }^{2}$ Grupo de pesquisa Integração das dimensões física, técnica e tática do Futebol e Futsal (EEFD/UFRJ e PPGCEE/UERJ); ${ }^{3}$ Laboratório do Exercício e Esporte (LABEES/UERJ); ${ }^{4}$ Instituto de Pesquisa da Capacitação Física do Exército.
} 


\begin{abstract}
Introduction: University sports play a very important role on the world sports scene. In Canada, college sports started a few years ago and have been reaping fruit in professional sports. Although in Brazil, the university sports system has similarities, but it has not shown success.

Objective: To compare the current situation of university sports in Brazil and Canada, through the perception of young people who had the experience of participating in university sports in both countries. Methods: Fourteen students who had the opportunity to experience university sports in both countries (Brazil and Canada). A structured questionnaire was built, applied twice, once for each country. The questions were segmented into the dimensions: training logistics, structural dimensions, game dimensions, organizational dimensions and overall dimensions. The reliability index of the instrument was verified using the Cronbach alpha coefficient. The Wilcoxon test was used to verify significant statistical difference between the questionnaires.

Results: The mean age of the sample was $22.85 \pm 2.63$. The students' responses about university sports in the countries are more negative for Brazil, reaching a total score of 30.93 against 76.64 in Canada. Where the affirmations of the questionnaires represented

\begin{tabular}{|l|}
\hline Keypoints \\
- A questionnaire was \\
developed to evaluate the \\
university sports model covering \\
five structural dimensions. \\
- The scores achieved showed \\
the differencebetween the \\
structure offered in both \\
countries. Brazil: 30.93 e \\
Canada: 76.94. \\
- The statistically significant \\
differences indicated the \\
deficient points in the Brazilian \\
model.
\end{tabular}
positive aspects, in all dimensions the score reached in the questionnaires related to Canada was higher than the questionnaire related to Brazil. The difference in relation to the university sports of the countries was significant. Conclusion: It is concluded that colleges in Canada have a sports department geared directly to university teams, an academic area and the sports field working together. This structure is lacking in university sports in Brazil for its success.
\end{abstract}

Keywords: sports, university, athletes.

\title{
Esporte universitário: percepção de atletas sobre os modelos brasileiro e canadense
}

\section{Introdução}

O esporte universitário está presente na maioria dos países. Nos dias de atuais, pode-se afirmar que o esporte universitário tem ganhado força, tornando-se uma área importante de fomento ao esporte de alto rendimento no cenário mundial(1). Tal tendência teve início em fins da década de 90. $\mathrm{Na}$ Europa, em 1999, foi criada a European University Sports Association (EUSA), uma associação de esportes universitários. Com o passar dos anos, o número de países membros dessa associação cresceu, o que favoreceu o desenvolvimento de novos modelos internos para o fomento do esporte(2). Muitos países europeus passaram a adotar o modelo de esporte universitário após a criação da associação europeia. Um dos primeiros países foi a Alemanha, que iniciou o esporte dentro das universidades ainda em 1999. Em 2009 a federação de esporte universitário alemã declarou que "o esporte universitário era uma parte indispensável do esporte alemão e do setor universitário". Nos Jogos Olímpicos de 2012, 42\% dos atletas da seleção alemã eram alunos-atletas das universidades(3).

Dentre inúmeras maneiras de estruturação do esporte universitário, existe um modelo que vem obtendo o melhor resultado em termos mundiais. Esse modelo é o utilizado pelos Estados Unidos da América, que em meados de 1850 começavam a falar do esporte universitário. Hoje em dia, nesse país, a maioria das faculdades possuem um estádio de futebol americano para 70 mil pessoas e uma arena de basquete com capacidade de 20 mil pessoas. Nesse modelo, o foco está no desenvolvimento de atletas universitários, 
pois, são das faculdades que saem os atletas profissionais; diferentemente de outros países em que os atletas profissionais se originam nos clubes(4).

O modelo seguido pelo Canadá é bem parecido com o do seu vizinho norte americano, porém, o país ainda não atingiu a excelência apresentada nos Estados Unidos. O Canadá iniciou o esporte universitário há mais tempo do que a Europa, por volta da década de 70 e vem progredindo no esporte universitário por meio da estruturação do modelo e, também, através da valorização dos seus alunos-atletas, oferecendo prêmios como forma de reconhecimento e agradecimento pelas realizações esportivas que os atletas obtêm por suas faculdades(5).

No Brasil, o esporte universitário teve início há quase 80 anos, por volta de 1940, porém, não teve sucesso em progredir nem em relação à fase de estruturação, tanto contexto nacional como em nível estadual e municipal(6). Tal situação é muito diferente do que acontece no Canadá, em relação à estruturação.

A legislação desportiva vigente no país sofreu muitas alterações ao longo dos anos com a implementação de leis que mudaram muito o panorama financeiro e legal do esporte(7-12), porém essas mudanças parecem não terem melhorado a situação do esporte universitário, pois, o Brasil não tem identificado novos talentos esportivos oriundos das competições universitárias, bem como não tem demonstrado resultados relevantes em competições internacionais a nível universitário.

O presente estudo teve como objetivo comparar a situação atual do esporte universitário no Brasil e no Canadá, por meio da percepção de jovens que tiveram a experiência de participar do esporte universitário em ambos os países.

\section{Métodos}

\section{Desenho de estudo e amostra}

Este estudo qualitativo(13) envolveu 14 alunos universitários, de ambos os sexos, que participaram de atividades esportivas representando suas instituições de ensino no Brasil e no Canadá, na condição de atletas universitários. Esses alunos são de diferentes cidades, abrangendo três cidades do Canadá e quatro cidades do Brasil. As cidades do Canadá foram: Fort Mc Murray, Medicine Hat e Olds. Todas da província de Alberta. As cidades brasileiras foram: Rio de Janeiro/RJ, Belo Horizonte/MG, Paracatu/MG e Chapecó/SC.

O critério de inclusão para a amostra utilizado no estudo foi o aluno ter vivenciado o esporte universitário em ambos os países como atleta no período de 2012 a 2017. Os critérios de exclusão foram a não voluntariedade do aluno em participar do estudo e o não preenchimento total dos questionários ou a incorreção no preenchimento dos mesmos.

\section{Aspectos Éticos}

Este estudo foi realizado dentro das normas éticas prevista na Resolução 466/2012 do Conselho Nacional de Saúde(18). Todos os participantes foram voluntários a participar do estudo e assinaram o termo de consentimento livre e esclarecido contendo informações sobre a natureza e objetivo do estudo.

\section{Questionário estruturado em dimensões}

Considerando não ser viável a abrangência de todos os assuntos conexos ao tema, foram eleitas cinco dimensões relacionadas aos aspectos estruturais do modelo de esporte universitário para a elaboração do questionário. Este tipo de técnica é de fácil aplicabilidade e pertinente, para ser empregada quando se trata de problemas cujos objetos de pesquisa correspondem a questões de cunho empírico, que envolve opinião do pesquisado(14).

O questionário foi elaborado seguindo os preceitos metodológicos para elaboração desta ferramenta(15) e apresenta-se no Quadro 1. Foram propostas cinco dimensões contendo afirmativas relevantes destinadas a diagnosticar a situação atual do esporte universitário: 1) Logística de treinamento; 2) Dimensões estruturais; 3) Dimensões de jogo; 4) Organização dos campeonatos; e 5) .

A primeira dimensão, "Logística de treinamento", aborda quesitos relacionados à dificuldade de agendamento, uniforme, demais materiais esportivos e transporte.

A segunda dimensão proposta para compor o instrumento foi "Dimensões estruturais" 
esportivas das faculdades. Destinou-se a examinar a estrutura adequada, levantando se havia departamento esportivo, complexo esportivo (quadras, campo e academia para musculação), além de registrar se há um estojo completo de primeiros socorros (kit médico) disponível aos atletas.

A terceira dimensão proposta foi "Dimensões de jogo". Apresentam-se duas afirmativas em relação aos jogos dos campeonatos: a universidade fornece dois uniformes para os times, para jogar como visitante e como mandante do jogo; quando há mando de campo, sua faculdade tem estrutura suficiente para que haja jogo.

A quarta dimensão, "Organização dos campeonatos". Procura levantar as seguintes informações, em relação aos campeonatos universitários: organização adequada do calendário e pontualidade dos jogos.

A quinta e última dimensão trata dos aspectos gerais do esporte universitário, "Dimensões gerais", tem por objetivo de levantar informações sobre: a importância dada ao esporte pela universidade; se o esporte gera algum benefício para a faculdade e/ou para o aluno; e se a universidade incentiva ou participa de alguma modalidade do esporte universitário.

O questionário foi construído com as questões apresentadas sob a forma de afirmativas e as opções de respostas foram graduadas pela escala de Likert(16). O participante deveria marcar na escala, a resposta que mais traduziu a sua opinião, baseando-se nesta escala. , os perguntados especificam seu nível de concordância com uma afirmativa com cinco alternativas ordenadas hierarquicamente de 1 a 5 , sendo: 1) Discordo totalmente; 2) Discordo parcialmente; 3) Não concordo nem discordo; 4) Concordo parcialmente e 5) Concordo totalmente. O Quadro 1 apresenta as dimensões e os respectivos itens componentes. As respostas positivas (concordantes com a afirmativa) foram codificadas como 1 (um) e as negativas ou nulas como 0 (zero). Assim, ao final, por meio da soma das respostas, foi calculado o escore do questionário.

Quadro 1 - Estrutura do questionário elaborado para avaliar a situação do esporte universitário, sob a percepção dos atletas

\begin{tabular}{|c|c|}
\hline DIMENSÃO & AFIRMATIVA \\
\hline $\begin{array}{l}\text { Logística de } \\
\text { treinamento }\end{array}$ & $\begin{array}{l}\text { 1. Em sua faculdade é fácil o agendamento de treinos para seu time. } \\
\text { 2. O seu time universitário possui uniforme de treino. } \\
\text { 3. A faculdade disponibiliza um material esportivo adequado para os treinos. } \\
\text { 4. Quando o time viaja para jogar, a faculdade fornece transporte de boa qualidade. }\end{array}$ \\
\hline $\begin{array}{l}\text { Dimensões } \\
\text { estruturais }\end{array}$ & $\begin{array}{l}\text { 1. A sua faculdade possui um departamento esportivo adequado. } \\
\text { 2. Os atletas possuem um kit médico completo a disposição. } \\
\text { 3. A faculdade possui um adequado complexo esportivo (quadras, campo, academia, } \\
\text { entre outros). }\end{array}$ \\
\hline $\begin{array}{l}\text { Dimensões de } \\
\text { jogo }\end{array}$ & $\begin{array}{l}\text { 1. A faculdade fornece uniformes de jogo para jogar como mandante e como } \\
\text { visitante. } \\
\text { 2. Quando há mando de campo, sua faculdade tem estrutura suficiente para que haja } \\
\text { jogo. }\end{array}$ \\
\hline $\begin{array}{c}\text { Dimensões } \\
\text { organizacionais }\end{array}$ & $\begin{array}{l}\text { 1. É adequada a organização dos campeonatos universitários. } \\
\text { 2. O calendário de jogos está de acordo com a expectativa dos times universitários. } \\
\text { 3. Depois dos jogos divulgados, é rara qualquer alteração de calendário. } \\
\text { 4. Os jogos sempre começam no horário marcado. }\end{array}$ \\
\hline Dimensões gerais & $\begin{array}{l}\text { 1. A minha faculdade da importância ao Esporte universitário. } \\
\text { 2. O esporte universitário gera benefícios tanto para os alunos quanto para a } \\
\text { faculdade. } \\
\text { 3. A minha faculdade me incentiva a fazer parte de algum esporte. }\end{array}$ \\
\hline
\end{tabular}

$\mathrm{O}$ instrumento passou por um processo de aprovação interna sob apreciação de três doutores com amplo conhecimento e experiência no esporte universitário, sendo 
testado por três alunos não pertencentes à amostra, antes da sua aplicação. E foi analisado quanto à consistência interna conforme descrito na seção análise estatística.

\section{Procedimentos de coleta de dados}

$\mathrm{O}$ mesmo questionário foi aplicado em referência ao Brasil e em referência ao Canadá.

\section{Análise estatística}

Foram feitas análises gráficas e descritivas: média, desvio padrão e valores percentuais das respostas. A confiabilidade quanto à consistência interna do instrumento utilizado foi avaliada pelo coeficiente Alfa de Cronbach, considerando-se como boa confiabilidade valores entre acima de $0,8(17)$. Para avaliar se houve diferença significativa entre os escores das avaliações dos participantes quanto à situação do esporte universitário no Canadá e no Brasil, utilizou-se o teste de Wilcoxon. O nível de confiança estabelecido para as análises foi de $95 \%$. O banco de dados foi construído no Programa SPSS versão $24.0{ }^{\circledR}$.

\section{Resultados}

Participaram do estudo os 14 alunos de ambos os sexos, convidados, com idades entre 18 e 26 anos $(22,85 \pm 2,63)$. O instrumento utilizado apresentou boa consistência interna 0,983 .

No Gráfico 1 exibe a comparação entre as respostas dos questionários respondidos pela amostra, sobre os aspectos do esporte universitário brasileiro e canadense dentro de cada dimensão, apresentando a diferença entre os percentuais das respostas. Observa-se que em todas as dimensões houve diferença estatisticamente significativa.

Em relação à realidade brasileira, todas dimensões do questionário tiveram a discordância como resposta predominante, sendo ainda que, em três afirmativas $100 \%$ da amostra discordou totalmente. Essas três afirmativas eram relacionadas a material esportivo para os treinos, disponibilidade de kit médico, ambas de "Dimensões estruturais" e alteração do calendário dos jogos depois da divulgação dos mesmos ("Dimensões

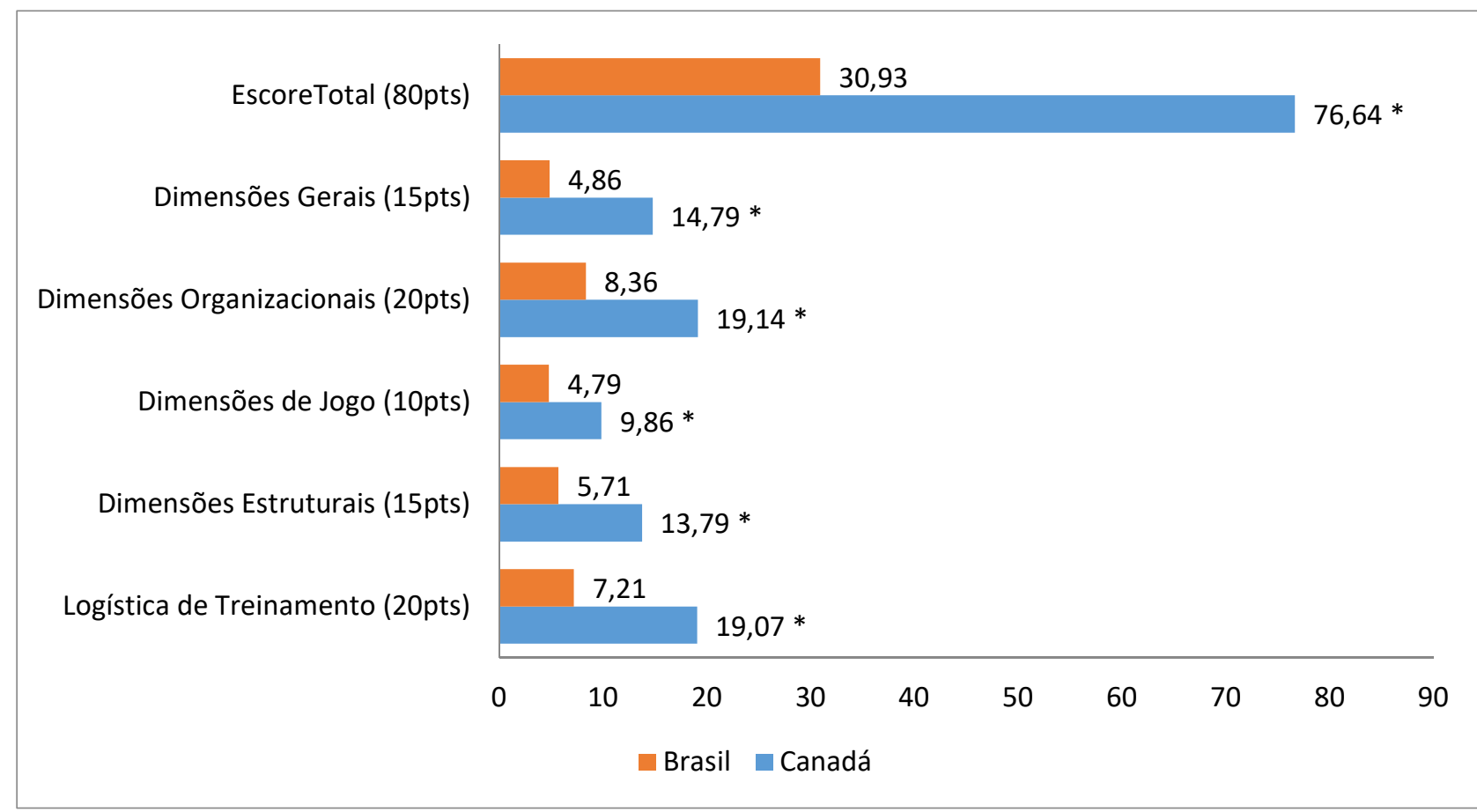

Gráfico 1 -Comparação entre as percepções dos atletas em relação aos aspectos estruturais do modelo de esporte universitário no Brasil e no Canadá. ( ${ }^{*}=p<0,01$ resultado do teste de Wilcoxon).

organizacionais"). Além disso, na afirmativa relacionada à importância dada pelas universidades brasileiras ao esporte, apenas dois alunos $(14,28 \%)$ da amostra responderam de forma neutra, que não discordam nem concordam. Os demais $(85,71 \%)$ discordaram da afirmativa. 
Ainda em se tratando de "Dimensões estruturais", em relação ao Brasil, uma das afirmativas destacou-se como a única que obteve o percentual de maior de concordância $(64,28 \%)$.

Em relação à dimensão "Logística de treinamento", no Brasil, a maioria (93\%) dos atletas universitários discordou de todas as afirmativas. Em relação a "Dimensões estruturais" esportivas das faculdades, $92,86 \%$ dos participantes discordou totalmente da afirmativa "A sua faculdade possui um departamento esportivo adequado" e $62,28 \%$ concordaram parcialmente com a afirmativa "A faculdade possui um adequado complexo esportivo (quadras, campo, academia, entre outros)". Em relação à afirmativa "Os atletas possuem um kit médico completo à disposição", $\quad 100 \%$ dos entrevistados discordaram no caso do Brasil.

Quanto a "Dimensões de jogo", no caso do Brasil, o índice de discordância na questão de a universidade fornecer dois uniformes para os times (visitante / mandante do jogo superou o de concordância, de maneira que um aluno relatou concordar e outro respondeu de forma neutra, os demais $(85,71 \%)$ discordaram desta afirmativa. Quanto a "Organização dos campeonatos" universitários, a maior parte dos entrevistados $\quad(85,71 \%) \quad$ discordou parcialmente das afirmativas. Apenas dois alunos $(14,3 \%)$ responderam que concordam parcialmente, todos os outros doze relataram como não sendo adequada a organização dos campeonatos universitários.

Quanto a "Dimensões gerais", 90,5\% discordou das afirmativas feitas, em relação ao Brasil, são elas: "A minha faculdade dá importância ao Esporte universitário", "O esporte universitário gera benefícios tanto para os alunos quanto para a faculdade" e "A minha faculdade me incentiva a fazer parte de algum esporte".

Em relação ao panorama do esporte universitário canadense, a concordância com as afirmativas do questionário foi quase unânime. Nas cinco dimensões existentes no questionário, em relação ao Canadá, mais de $50 \%$ concordou totalmente com as afirmativas feitas, e houve pontuação positiva em 100\% das afirmativas. No quesito material esportivo, $100 \%$ concordaram que as faculdades canadenses possuem o material adequado para utilização nos treinos. Sobre o transporte utilizado, nas viagens de final de semana, para os jogos como visitante, apenas um entrevistado concordou parcialmente, resultando um total de $92,31 \%$ que concordou totalmente.

A dimensão direcionada a analisar a parte de estruturação obteve um resultado muito superior em favor da realidade canadense, todos os alunos concordaram que as faculdades canadenses possuem um departamento esportivo adequado. Quanto à qualidade da "Organização dos campeonatos", em relação ao Canadá, $50 \%$ dos participantes concordaram totalmente e $50 \%$ concordaram parcialmente.

Em "Dimensões gerais" do esporte nas universidades canadenses, 92,9\% avaliaram positivamente os três quesitos componentes.

\section{Discussão}

O presente estudo teve por objetivo descrever e comparar a situação do esporte universitário no Brasil e no Canadá. Os resultados mostraram que, o panorama do esporte universitário brasileiro apresentou um escore muito inferior nas dimensões adotadas pelo estudo quando comparado ao canadense. Dentro de um total possível de ser alcançado de 80 pontos (somatório das concordâncias relativas às afirmativas), o escore total alcançado pelas universidades no Brasil foi de 30,93 contra 76,74 referente ao cenário no Canadá.

Em relação à dimensão "Logística de treinamento", no Brasil, a maioria (93\%) dos atletas universitários discordou de todas as afirmativas e trata-se de questão de fundamental importância para o desenvolvimento do esporte. De acordo com Barbosa(19), sem treinamento, sem material específico e sem organização, os times não conseguem a mesma evolução que teriam, caso tivessem tais elementos disponíveis. Quanto à organização para execução do planejamento do treinamento ("Logística de treinamento"), pelas respostas dos alunos-atletas, o modelo esportivo no âmbito universitário canadense é muito superior comparado ao brasileiro e os resultados sugerem que os aspectos focalizados, quanto ao treinamento, são 
levados a sério pelas faculdades/universidades canadenses. Nesse contexto, um ponto importante que deve ser destacado é que, de acordo com os participantes do estudo, não existe burocracia para o agendamento dos treinos no Canadá, o que facilita o planejamento do treinador, possibilitando quantificar o treino que realizará com sua equipe. Além disso, a maioria dos participantes concordou que as universidades canadenses proporcionam uniforme para treinar/competir (100\% concordou totalmente ou parcialmente com esta afirmativa).

Ainda em "Logística de treinamento", no quesito material esportivo, diferentemente das respostas relacionadas ao Brasil, todos concordam que as faculdades canadenses possuem o material adequado para utilização nos treinos. Esse fator é favorável aos atletas canadenses, já que treinar com bolas de qualidade e possuir material adequado para o complemento do treino, facilita e favorece a evolução das equipes. Sobre o transporte utilizado nas viagens de final de semana para os jogos como visitante, apenas um entrevistado concordou parcialmente, resultando um total de $92,31 \%$ que concorda totalmente que, no Canadá, o transporte das equipes é de boa qualidade.

Em relação a "Dimensões estruturais" esportivas das faculdades brasileiras, todos os alunos-atletas discordaram totalmente da afirmativa "Os atletas possuem um kit médico completo à disposição". Ainda nesta mesma dimensão, 92,86\% da amostra discordou totalmente da afirmativa "A sua faculdade possui um departamento esportivo adequado", porém na última afirmativa desta dimensão a opinião dos alunos se dividiu bastante, já que $62,28 \%$ concordaram parcialmente com a afirmativa "A faculdade possui um adequado complexo esportivo (quadras, campo, academia, entre outros)". Os resultados sugerem que a maioria das faculdades apresenta um complexo adequado para a realização dos treinos. Essa questão favorece as universidades, não havendo a necessidade de deslocamentos, empréstimos ou locação de outros locais(20). As faculdades brasileiras possuem quadras, academias e campos, sendo plausível que esse não seja a principal causa do insucesso do esporte universitário. Não obstante, no quesito facilidade de agendamento na dimensão relacionada a treinamento, a resposta foi negativa. Desta forma, observa-se dificuldade de acesso aos locais de treino, apesar de existir complexo esportivo adequado(21).

Há vários problemas na estrutura ("Dimensões estruturais") no modelo brasileiro de esporte universitário. Um dos principais problemas é a falta de um departamento esportivo, o que dificulta ou até mesmo inviabiliza a existência do esporte dentro das universidades(19). O departamento esportivo na faculdade é responsável pelo gerenciamento do esporte, que deve estruturar as equipes e garantir uma organização básica para os times(11). Como consequência desse problema, observa-se o surgimento de outros como a segurança dos atletas. Pois, no que se refere a material destinado à primeiros socorros, essa foi uma das poucas afirmativas que $100 \%$ dos entrevistados discordaram em relação ao Brasil. Durante um jogo de futebol, por exemplo, é frequente a ocorrência de lesões, nesse contexto, há necessidade de que $\mathrm{o}$ atendimento de primeiros socorros básicos esteja disponível aos atletas.

De modo semelhante aos resultados na dimensão "Logística de treino", em "Dimensões estruturadas" os resultados em favor da realidade canadense, também, foram muito superiores. Quase todos os atletasalunos concordaram que as faculdades canadenses possuem um departamento esportivo adequado. Tais achados indicam que há uma base para o desenvolvimento do esporte dentro das instituições, e que o esporte faz parte da universidade naquele país.

Quanto a "Dimensões de jogo", no caso do Brasil, o índice de discordância $(85,71 \%)$ na questão de a universidade fornecer dois uniformes para os times (visitante / mandante do jogo superou o de concordância. Portanto, os resultados indicam que as faculdades brasileiras não fornecem o material básico para que haja um jogo universitário, prejudicando o desenvolvimento do esporte universitário, o que para Barbosa(19) influencia diretamente o desenvolvimento do futuro profissional. Em relação à existência de estrutura suficiente para sediar o jogo ("Dimensões de jogo"), o percentual de alunos que concordou foi 
ligeiramente maior, indicando que, talvez seja possível ter mando de jogo em algumas das faculdades. Esse fator aumentaria a possibilidade de torcida para a sua equipe, favorecendo a visibilidade do esporte universitário(22).

Em relação ao Canadá, em "Dimensão jogos", os resultados mostram uma concordância total com as afirmativas de $92,9 \%$ dos participantes. O aspecto de a faculdade fornecer para os jogos dois uniformes diferentes, um para jogar como mandante e outro como visitante foi o único que teve $100 \%$ de concordância no caso das universidades canadenses. Além disso, todos concordaram que as universidades canadenses possuem complexos esportivos adequados, e assim, os times conseguem ter jogo como mandante em suas faculdades. Este fator atrai público e visibilidade para a equipe e para a faculdade fomentando o esporte universitário.

Quanto à organização dos campeonatos universitários ("Dimensões organizacionais"), a maior parte dos entrevistados $(85,71 \%)$ discordou parcialmente das afirmativas. A minoria dos alunos (14,3\%) concordou parcialmente, todos os demais relataram como não sendo adequada essa organização, demonstrando, assim, ser desfavorável a realização dos campeonatos universitários executado pela Confederação Brasileira de Desporto Universitário (CBDU). Starepravo et al.(21) identificaram que o estado está diretamente relacionado com o desenvolvimento do esporte universitário no Brasil, principalmente por manter com este uma relação de interdependência por meio do financiamento público do esporte, embora a CBDU seja uma entidade de cunho privado.

Ainda em relação à organização dos campeonatos, os calendários dos jogos não se apresentam de acordo com a expectativa dos atletas. Além disso, não é rara a alteração de tabela após a divulgação dos jogos. Cem por cento da amostra discordou da afirmativa de que raramente há alteração do calendário dos jogos após a divulgação dos mesmos. Cada time possui seu planejamento feito de acordo com o calendário divulgado pela organização e pode ser prejudicado com as mudanças inesperadas ocorridas com o campeonato em curso. Não obstante, a maioria apontou que os jogos nem sempre começam no horário marcado pela organização, outro problema básico existente no modelo brasileiro.

No Canadá, em "Dimensões organizacionais", o trabalho das confederações parece ser bem executado já que, os resultados mostram que a organização dos campeonatos é positiva para os alunos. Nesta afirmativa, $100 \%$ dos participantes concordaram total ou parcialmente, pontuando positivamente na composição do escore total. Os estudantes também concordaram que o calendário de jogos universitários no Canadá está de acordo com a expectativa dos times. De acordo com Morrow(23) as temporadas começam e terminam em épocas próximas, facilitando assim a pré-temporada e a temporada de jogos, indicando que a organização do calendário esportivo é elemento importante para o desenvolvimento do esporte universitário.

Em "Dimensões gerais", 90,5\% discordaram das afirmativas propostas. Tais resultados sugerem que as universidades no Brasil não apoiam e não incentivam $\mathrm{o}$ esporte universitário. Enquanto que, dentro das universidades canadenses, houve grande predominância da opção de resposta "Concordo totalmente", totalizando 92,9\%. Os alunos-atletas concordaram que o esporte universitário tem uma grande importância dentro de suas faculdades. Desse resultado, observa-se que as universidades canadenses tratam o aspecto esportivo tão bem quanto o aspecto acadêmico, indicando que o esporte integra perfeitamente o processo educativo e formativo dos alunos(24).

Diferentemente do que ocorre no Brasil, os alunos apontaram que as faculdades no Canadá incentivam sua participação em algum time universitário, oferecendo incentivos como o fato de poder estudar em uma instituição de qualidade e com $100 \%$ de bolsa. Além disso, toda a facilidade relatada no estudo impulsiona uma adesão de novos atletas e a permanência dos antigos. Este fato reflete o histórico positivo do planejamento estratégico(23).

De modo geral, em comparação com a realidade canadense, o esporte universitário brasileiro, na percepção de atletas com vivências em ambos os países, demonstrou estar muito aquém em todos os quesitos avaliados pelo instrumento utilizado neste 
estudo. As respostas para o modelo canadense foram, em sua maioria, positivas. Nesse contexto, observa-se que, no Brasil, embora a Lei ${ }^{\circ}$ 8.672/93 ("Lei Zico) e, posteriormente, a Lei $n^{\circ}$ 9.615/98 ("Lei Pelé") tenham dado autonomia de organização para a realização de competições desportivas em nível regional às universidades, pouco foi modificado na estrutura do esporte universitário, ainda que existam as Associações Atléticas Acadêmicas (AAA), entidades básicas de organização do esporte das universidades(11), que se constituem em centros diretamente responsáveis pela prática esportiva no âmbito dessas Instituições e, aparentemente, não têm boa interação com a CBDU, sendo que funcionam de forma desvinculada, resultando em competições universitárias mal organizadas e nada atrativas no Brasil(21).

Comparando a situação de ambos modelos, em contraste com o Brasil, no Canadá, das cinco dimensões existentes no questionário, em todas as afirmativas apresentadas, mais de $50 \%$ dos participantes concordaram totalmente. Tais achados demonstram que o modelo canadense está bem desenvolvido, concordando com os resultados de estudo de Hall(25), que concluiu que o esporte universitário canadense é favorável àqueles que fazem parte dele.

\section{Pontos fortes e limitações do estudo}

Este estudo foi, até onde se sabe, o primeiro a comparar a situação atual do esporte universitário no Brasil e no Canadá, por meio da percepção de jovens que tiveram a experiência de participar do esporte universitário em ambos os países. Tal análise contribui para o conhecimento em Gestão Esportiva, levantando novas necessidades de investigação para melhor desenvolver o esporte universitário no Brasil. Uma das limitações do estudo refere-se ao amostral reduzido que, entretanto, justifica-se pela evidente pequena quantidade de alunos universitários atletas que tenham tido a oportunidade de vivenciar o esporte em universidades de ambos os países. Nessa perspectiva, a relevância do estudo permanece, posto que foi o primeiro a realizar tal comparação e a contribuição ao conhecimento é evidente.

\section{Conclusão}

A partir dos resultados encontrados observase que o modelo seguido pelo esporte universitário brasileiro, no geral, não é favorável aos alunos-atletas. Das cinco dimensões escolhidas, $100 \%$ tiveram respostas negativas. Os resultados mostram condições desfavoráveis em todas as áreas do esporte universitário brasileiro. Problemas encontrados na estrutura das universidades como também na organização dos jogos acarretam na falta de interesse dos alunos pelo esporte universitário, e a consequente falta de espectadores nos jogos. Todos esses óbices dificultam o trabalho das federações para conseguir patrocínios e fomentar o esporte universitário.

Em oposição à situação no Brasil, observando os resultados encontrados sobre o esporte universitário no Canadá. Os alunos demonstraram satisfação em fazer parte do esporte universitário canadense e as cinco dimensões escolhidas apresentaram resultados positivos, sendo que o escore total do Canadá $(76,74)$ foi muito maior do que o do Brasil $(30,93)$.

Os resultados do presente estudo sugerem haver harmonia entre as áreas do esporte universitário e acadêmica nas universidades no Canadá. Estes achados são novos e servem de ponto de partida para novas investigações sobre o tema.

Concluiu-se que há falta de diversos aspectos estruturais que indicam falhas administrativas e objetividade ao modelo de esporte universitário no Brasil, que têm implicações em seu sucesso.

\section{Declaração de conflito de interesses}

Não há nenhum conflito de interesses em relação presente estudo.

\section{Declaração de financiamento}

Financiamento próprio.

\section{Referências}

\section{Hatzidakis G. Esporte Universitário.} Internet. Disponível em: http://www.atlasesportebrasil.org.br/textos/ 72.pdf. Acessado em: 04 de julho de 2018. Rio de Janeiro. 2006; 1019-1021. 
2. Sebkova H. Accreditation and quality assurance in Europe. Higher Education in Europe. 2002; 27: 239-47.

3. Pfister G and Radtke S. Sport, women, and leadership: Results of a project on executives in German sports organizations. European Journal of Sport Science. 2009; 9: 229-43.

4. Thelin J. Edwards J. History of athletics in US colleges and universities. 2015. Internet. Disponível em: http:/education.stateuniversity.com/pages/ 1846/College-Athletics-HISTORY-

ATHLETICS-IN-U-S-COLLEGES-

UNIVERSITIES.html. Acessado em: 04 de julho de 2018.

5. Pedro MAD, Paipe G, González-García RJ and Carvalho MJ. O esporte e a eficácia organizacional: Uma revisão da literatura. Revista de Gestão e Negócios do Esporte. 2017; 2(1):64-80.

6. Hossein E, Ramezanineghad R, Yosefi B and Sajjadi SN. Compressive review of organizational effectiveness in sport. Choregia. 2011;7:5-21.

7. Vargas ALDS, Lamarca BRDC and Pinto RJDC. As diferenças entre o direito a imagem e direito de arena no contexto das leis No. 9.615/1998, 9.981/2000 e $10.672 / 2003$ e do projeto de lei $\mathrm{N}^{\mathrm{o}}$ 5.186/2005. Revista Internacional de Investigación en Ciencias Sociales. 2009;5:191-212.

8. SILVA DAS. Evolução histórica da legislação esportiva brasileira: do Estado Novo ao século XXI. Revista Brasileira de Educação Física, Esporte, Lazer e Dança. 2008;3:69-78.

9. Duch FF. Interface Extensão Universitária e Cultura Interdisciplinar. Dissertação (mestrado)-Universidade Braz Cubas. Programa de Pós-Graduação em Semiótica, Tecnologias de Informação e Educação. Mogi das Cruzes: UBC, 2006. 97 f, 2015.

10. Brasil. Lei ${ }^{\circ} 10.264$, de 16 de julho de 2001. Presidência da República. BrasiliaDF.
11. Starepravo FA, Reis L, Mezzadri FM and Marchi W. O esporte universitário no Brasil: uma interpretação a partir da legislação esportiva. Esporte e Sociedade, ano. 2010; 5(14):1-23.

12. Lei Agnelo/Piva. [Online] Portal Brasil 2016. Disponível em: http://www.brasil2016.gov.br/ptbr/incentivo-ao-esporte/lei-agnelo-piva. Accessado em: 04 de julho de 2018.

13. Thomas JR, Nelson JK, Silverman SJ. Métodos de pesquisa em atividade física. Porto Alegre, RS: ArtMed; 2007. 396 p.

14. Chaer G, Diniz RRP and Ribeiro EA. A técnica do questionário na pesquisa educacional. Revista Evidência. 2012;7(7):251-266.

15. Kauark FS, Manhães FC, Medeiros CH. Metodologia da pesquisa: um guia prático. Ibicaraí-BA. Via Lterattum Editora; 2010. 96p.

16. Júnior SDS and Costa FJ. Mensuração e escalas de verificação: uma análise comparativa das escalas de Likert e Phrase Completion. PMKT-Revista Brasileira de Pesquisas de Marketing, Opinião e Mídia. 2014;15:1-16.

17. Streiner DL. Being inconsistent about consistency: When coefficient alpha does and doesn't matter. Journal of Personality Assessment. 2003;80:217-22.

18. CNS. Conselho Nacional de Saúde do Miistério da Saúde. Resolução $n^{\circ} 466 / 2012$. Diretrizes e normas regulamentadoras de pesquisas envolvendo seres humanos. Brasília, DF. 2012.

19. Barbosa CG [UNESP. A gestão pública do esporte universitário brasileiro: a bola não deve entrar por acaso. Tese de Doutorado. UNESP, 2017; Available from: https://repositorio.unesp.br/handle/11449/1 51837 Accessado em: 04 de julho de 2018.

20. Da Cunha Bastos F. Administração Esportiva: área de estudo, pesquisa e perspectivas no Brasil. Motrivivência. 2003: 295-306.

21. Starepravo FA, Reis LJ de A, Mezzadri FM, Marchi Júnior W. Esporte universitário 
brasileiro: uma leitura a partir de suas relações com o Estado. Revista Brasileira de Ciências do Esporte. [Online] 2010;31(3): 131-148. Available from: doi:10.1590/S0101-32892010000300009.

22. Murata GHY [UNESP. Marketing esportivo e liderança: aspectos relevantes do esporte brasileiro. Aleph. 2013; $34 \mathrm{f}$.

23. Morrow D, Wamsley KB. Sport in Canada: A History. Oxford University Press; 2016. 360 p.

24. Silk ML, Andrews DL, Cole CL. Sport and corporate nationalisms. Berg; 2005. $314 \mathrm{p}$.

25. Hall MA. The Girl and the Game: A History of Women's Sport in Canada, Second Edition. University of Toronto Press; 2016. 425 p. 